\title{
ON THE VERTICAL RESPONSE OF FIBER REINFORCED ELASTOMERIC ISOLATORS (FREIS) UNDER COMBINED VERTICAL AND LATERAL LOADING
}

\author{
Simone Galano ${ }^{1,2}$ \\ 1, Department of Structures for Engineering \& Architecture, University of Naples Federico II \\ Napoli, via Claudio 21, Naples 80125, Italy \\ simone.galano@unina.it \\ ${ }^{2}$, Department of Civil Engineering \& Construction Engineering Management, California State University \\ Long Beach, \\ Long Beach, CA, USA \\ Simone.Galano@csulb.edu
}

\begin{abstract}
The vertical behavior of Fiber Reinforced Elastomeric Isolators (FREIs) is controlled by geometric and mechanical parameters, such as primary and secondary shape factors, shear modulus of the rubber and effective compressive modulus of the rubber-reinforcements compound. Several studies dealt with the vertical properties of the bearings, deriving analytical formulations in function of the bearing geometry and materials' properties. These relations have been derived under pure compression, considering the interaction between single rubber layers and flexible reinforcements. As of today, few works have been proposed on the influence of the horizontal displacement imposed on the bearing, i.e. no interaction between vertical pressure and horizontal displacement on the vertical stiffness and the compressive modulus has been accounted for. In this paper, a numerical study on the influence of the primary and secondary shape factor, the shear modulus of the rubber and the vertical pressure on the vertical properties of the FREIs is presented. In a first stage the behavior of square shaped FREIs under pure compression is examined and relative outcomes are presented. Then the influence of the horizontal displacement on the vertical response of the bearings is considered. Interesting results on the trend of the vertical stiffness and compressive modulus are obtained and useful considerations on the stability of FREIs are provided.
\end{abstract}

Keywords: Fiber-Reinforced Elastomeric Isolators, Vertical Properties, Elastomeric Seismic Isolators, Rubber bearings, Seismic Isolation.

\section{INTRODUCTION}

Fiber-reinforced elastomeric isolators (FREIs) were introduced as alternative seismic isolation devices to steel-reinforced elastomeric isolators (SREIs). Several advantages in cost and manufacturing result replacing steel reinforcements with fiber fabrics such as:

- Fiber fabrics are much lighter than steel, despite having similar elastic mechanical properties. With the same volume of reinforcement, fiber-reinforced bearings are therefore lighter than steel-reinforced ones [1].

- Fiber-reinforced bearings can be produced in a cheaper and faster manufacturing process, i.e. cold vulcanization process [2]. 
- From larger sized pads, it would be possible to cut bearings of the required size and different shapes (i.e. strip-shaped) [1, 3, 4].

Using fiber-reinforced bearings in unbonded configuration, i.e. allowing the marginal areas of the bearing to detach from the supports during horizontal displacement resulting in the rollover deformation, further advantages can be achieved.

- As the marginal portions of the bearing gradually detach from the supports during horizontal displacement, the contact area reduces and consequently the lateral stiffness of the bearing, increasing the efficiency of the isolation system [5].

- The tensile stresses that would develop in the marginal area of the bearing in bonded configuration are greatly reduced when these marginal portions can detach from the supports [6].

- The rollover deformation proceeds until the initial vertical faces of the bearing fully touch the supports becoming horizontal and increasing the lateral stiffness of the bearing. As this occurs at large deformations, the isolation system acquires greater stability at large displacements $[5,6]$.

The response of fiber reinforced elastomeric isolators has been studied in several works. Analytical formulations for vertical ( $[1,7,8,9])$ and horizontal stiffness $([10,11,12,13])$ have been proposed, and a number of other studies have investigated the mechanical properties of bearings through experimental tests ( $[4,3,14,15,16,17,18,19,20,21])$ and finite element analysis ( [22, $23,24,25])$. Furthermore, analytical models for static and dynamic response have been proposed ( $[26,27,28,29,30])$.

The vertical stiffness of an elastomeric bearing is primarily controlled by two parameters [31]: primary shape factor $S_{1}$ (defined as the ratio between the loaded area and the area free to bulge) and effective compressive modulus $E_{c}$ (defined as the instantaneous elastic modulus of the rubberreinforcements compound). The lateral response of an unbonded FREIs can be stable or unstable (Figure 1). In the first case, the bearing shows a positive tangent lateral stiffness throughout the lateral deformation; in the second case the horizontal tangent stiffness of the bearing could decrease until becoming equal or less than zero. The horizontal response is mainly controlled by the secondary shape factor [32], that is the ratio between the base side in the horizontal displacement direction and the total height of the bearing $\left(S_{2}=B / H\right.$ ). Current codes require stable behavior to bearings $[33,34,35]$, i.e. a sufficiently high secondary shape factor. Several experimental and numerical studies have shown that a stable behavior is ensured if $S_{2}$ is at least equal to 2.5 [36, 37, $36,38]$. 


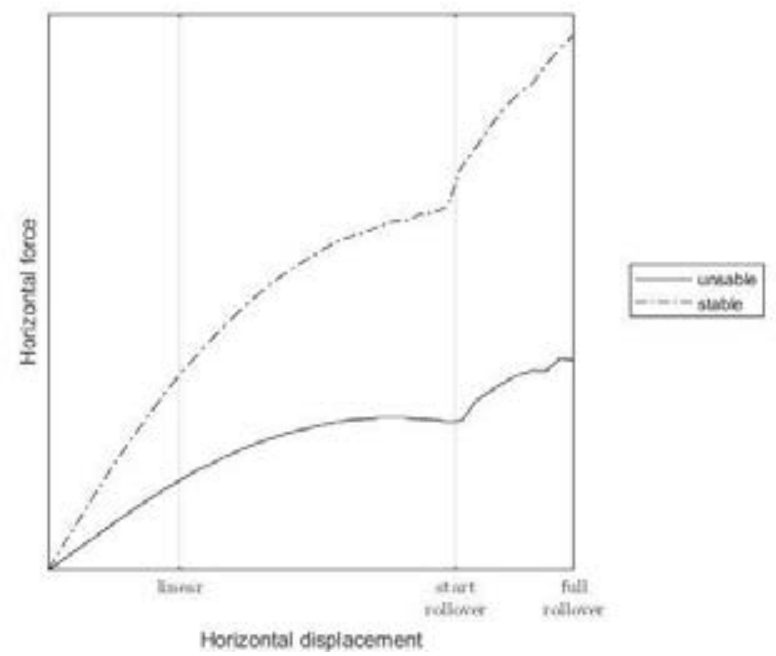

Figure 1: Stable vs unstable lateral behavior of U-FREIs under combined axial and shear load.

Elastomeric bearings require larger vertical stiffness than horizontal one (e.g. at least two order of magnitude) to support the weight of the superstructure and avoid potential rocking motions [39, 31]. Comparing the vertical stiffness under pure compression and the secant horizontal stiffness of a generic bearing with a sufficiently large primary shape factor, this requirement is easily met. However, during the rollover of the lateral displacement, the contact area between the bearing and the supports is reduced, which also reduces the vertical stiffness of the bearing. It is therefore necessary to take this reduction into account when comparing vertical and horizontal stiffness. In a safety evaluation, the vertical and horizontal stiffnesses could be compared at a given level of horizontal displacement.

However, few studies have considered the reduction of vertical stiffness with increasing horizontal displacement [40] and there is a lack of knowledge on the influence of the main geometric and mechanical parameters on the interaction between vertical and horizontal response. This work proposes a large number of finite element analysis on square shaped FREIs, varying different mechanical and numerical parameters. The influence of the primary and secondary shape factor on the combined vertical and horizontal response is taken into account.

\section{FINITE ELEMENT ANALYSIS: OVERVIEW}

Several different values for two combinations of geometric and mechanical parameters were considered:

- Geometric: base dimensions $B=2 a=2 b$ and thickness of the elastomeric layers $t_{e}$;

- Mechanical: shear modulus $G$ of the elastomer and vertical applied pressure $\sigma_{v}$.

In addition, four parameters were also kept constant: the total height of the bearing $H=n t_{e}+(n-1) t_{f}$, the equivalent thickness of the fiber reinforcement $t_{f}$, Young's modulus $E_{f}$ of

the fiber fabric and its Poisson's ratio $v_{f}$. All the considered parameters are listed in Table 1. By permuting the parameters shown in Table 1, a total of 240 numerical models were obtained, with 9 different secondary shape factors, ranging from 1 to 5 , and 16 primary shape factors, from 5 to 62.5 . 
Table 1: Variable parameters considered in the finite element analysis.

\begin{tabular}{cccccccc}
\hline $\begin{array}{c}2 a=2 b=B \\
{[\mathrm{~mm}]}\end{array}$ & $\begin{array}{c}H \\
{[\mathrm{~mm}]}\end{array}$ & $\begin{array}{c}t_{e} \\
{[\mathrm{~mm}]}\end{array}$ & $\begin{array}{c}G \\
{[\mathrm{MPa}]}\end{array}$ & $\begin{array}{c}\sigma_{v} \\
{[\mathrm{MPa}]}\end{array}$ & $\begin{array}{c}E_{f} \\
{[\mathrm{MPa}]}\end{array}$ & $\begin{array}{c}t_{f} \\
{[\mathrm{~mm}]}\end{array}$ & $\begin{array}{c}v_{f} \\
{[-]}\end{array}$ \\
\hline 100 & 100 & 2 & 0.4 & 2 & 70000 & 0.1 & 0.1 \\
150 & & 5 & 0.8 & 4 & & & \\
200 & & & 1.2 & 6 & & \\
250 & & & 8 & & \\
300 & & & & & \\
350 & & & & & & \\
400 & & & & & & \\
450 & & & & & & \\
500 & & & & & & \\
\hline
\end{tabular}

All the finite element analyses were carried out using MSC Marc [41], a general purpose FEA software optimized for non-linear analyses. This software allows careful modeling of nonlinear behavior, with a wide choice of hyperelastic material models for elastomers.

The elastomer was modeled using a Neo-Hookean hyperelastic material. When the compressibility of the elastomer is taken into account, the strain energy density function can be obtained as [42]:

$$
W=C_{1}\left(I_{1}-3-2 \ln J\right)+C_{2}(J-1)^{2}
$$

where $C_{1}$ and $C_{2}$ are material constants, $I_{1}=\lambda_{1}^{2}+\lambda_{2}^{2}+\lambda_{3}^{2}$ the first invariant of the right CauchyGreen deformation tensor and $J=\lambda_{1} \lambda_{2} \lambda_{3}$ the determinant of the deformation gradient.

The strain energy density function for an incompressible Neo-Hookean material is given by:

$$
W=C_{1}\left(I_{1}-3\right)
$$

obtained from (2.1) when $J=1$. The two constants $C_{1}$ and $C_{2}$ can be correlated to the Lamè constants:

$$
\begin{aligned}
& C_{1}=\frac{G}{2} \\
& C_{2}=\frac{\lambda}{2}=\frac{K}{2}-\frac{G}{3}=\frac{K}{2}-\frac{2 C_{1}}{3}
\end{aligned}
$$

The fiber reinforcement layers were modeled using a linear elastic model, with each layer is fully defined by the three parameters shown in Table $1\left(E_{f}, v_{f}\right.$ and $\left.t_{f}\right)$. The elastomeric layers were modeled using a four-node, isoparametric, quadrilateral elements, implemented for plane-strain incompressible applications [43]. The reinforcement layers were modeled using an isoparametric, plane-strain, 2-node rods or cords (i.e. rebars), in conjunction with the 4-node plane strain continuum elements used for the rubber layers [43]. Top and bottom supports were modeled using rigid contact curves. A "touch" type of contact between the bearing and the rigid supports has been set, with a friction coefficient of 1 , a reasonable value to describe the friction at the rubber-steel interface [44]. 
2D models were used for this study, taking into account the out of plane dimension of the bearing, resulting in equivalent 3D models (Figure 2).
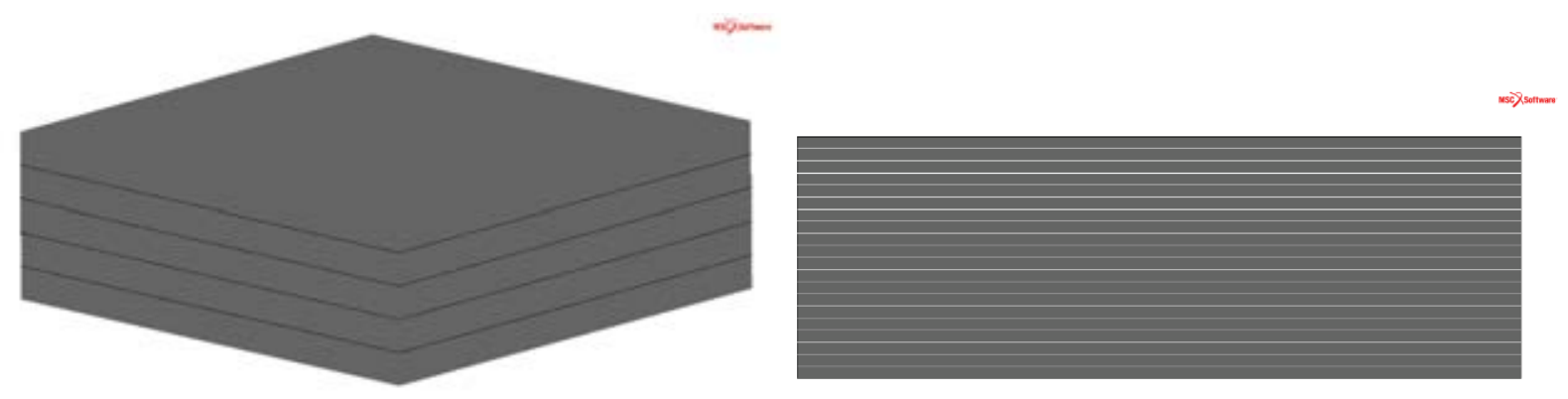

Figure 2: Full 3D numerical model vs equivalent 3D FEA model.

\section{FINITE ELEMENT ANALYSIS RESULTS: VERTICAL STIFFNESS}

\section{1 - Pure compression}

The trend of vertical stiffness under four different values of vertical pressure (from 2 to $8 \mathrm{MPa}$ ) and for different values of the shear modulus is shown in Figure 3 and Figure 4 for $t_{e}=2 \mathrm{~mm}$ and $t_{e}=5$. In each graph, the vertical stiffness is plotted with respect to the vertical displacement (primary axes, black curves) and to the primary shape factor (secondary axes, gray curves); for each curve, each marker stands for a different secondary shape factor, i.e. one of the bases listed in Table 1 being the total height constant. This representation allows to simultaneously monitor the interaction between mechanical and geometric parameters on the vertical stiffness of the bearings.

The significant role of the primary shape factor $S_{1}$ is confirmed, i.e. an approximately quadratic relationship with the vertical stiffness is found. The vertical stiffness does not vary appreciably with the vertical pressure applied as $S_{1}$ varies. With the same $S_{1}$, even if the vertical pressure is four times higher, the vertical stiffness is almost constant. A clear change of response is appreciable in vertical displacements. The vertical response may be split into two ranges of ${ }^{S_{2}}$; for a generic $G$ modulus and a generic vertical pressure ${ }^{\sigma_{v}}$ :

- If $S_{2}>2.5$ : the vertical displacement varies slightly between one bearing and another, varying less and less and tending to a vertical asymptote as $S_{2}$ increases, regardless of mechanical parameters (pressure and shear modulus).

- If $S_{2} \leq 2.5$ : displacements under vertical load vary more and more as $S_{2}$ decreases..

The transition value $S_{2}=2.5$ agrees with previous findings from literature regarding the stability of bearings subjected to simultaneous vertical and horizontal load: bearings with a larger value of $S_{2}$ have a more stable behavior and are less dependent on mechanical parameters ( $[37,38])$. 

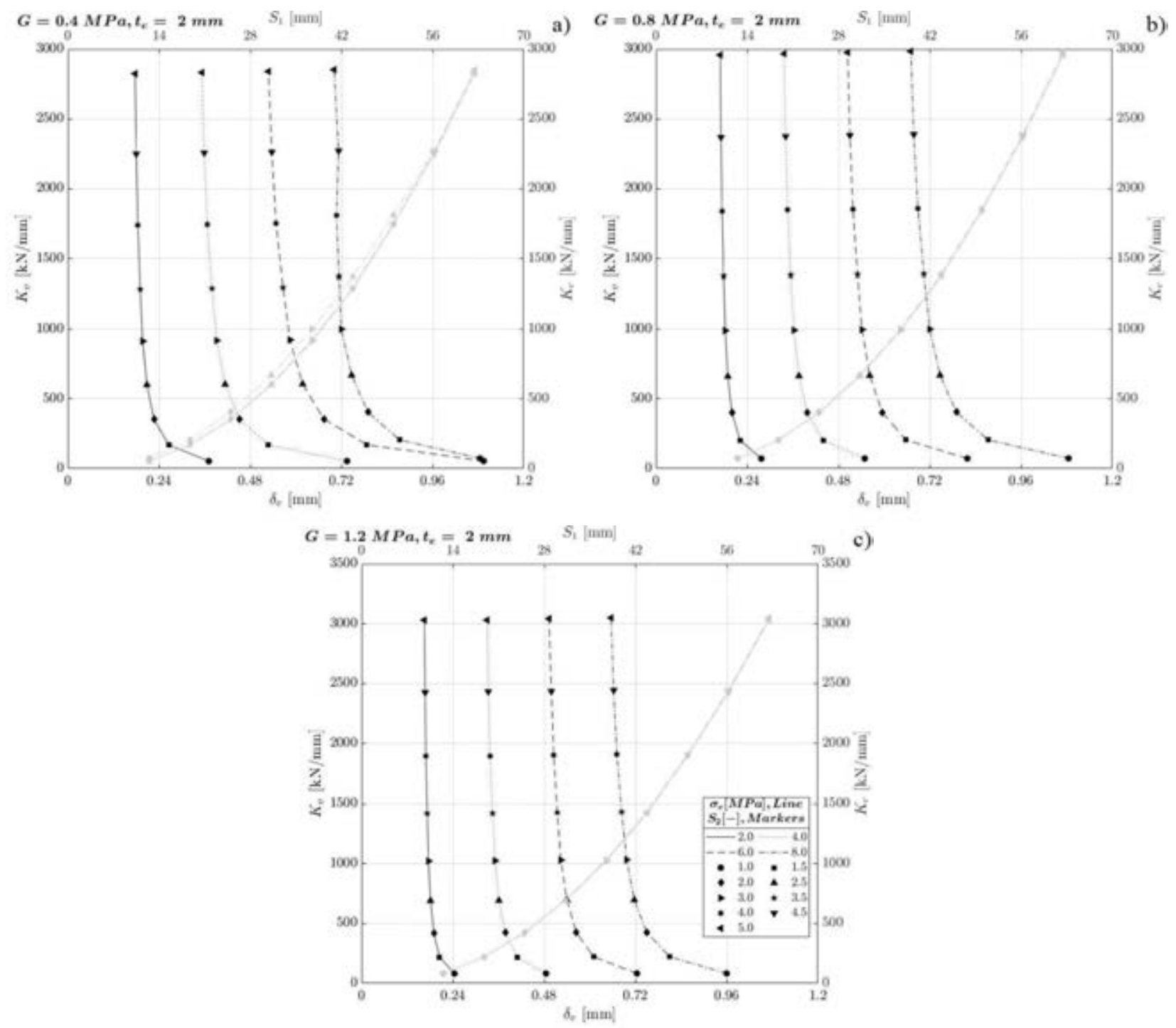

Figure 3: Vertical stiffness under pure compression for different vertical pressure, primary and secondary shape factor, $t_{e}=2 \mathrm{~mm}:$ a) $G=0.4 \mathrm{MPa}$, b) $G=0.8 \mathrm{MPa}$. c) $G=1.2 \mathrm{MPa}$ 

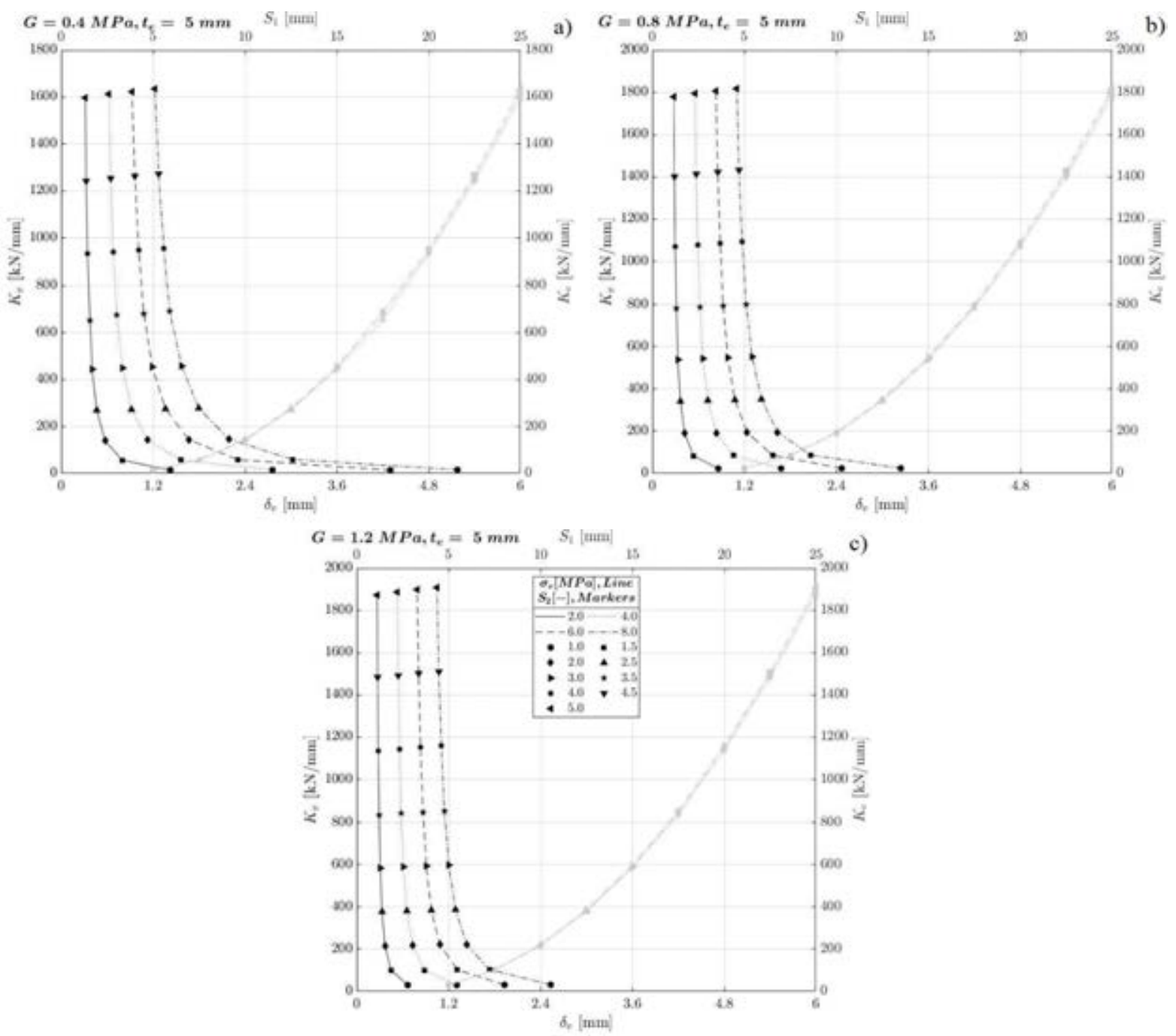

Figure 4: Vertical stiffness under pure compression for different vertical pressure and secondary shape factor, $t_{e}=5$ mm: a) $G=0.4 \mathrm{MPa}$, b) $G=0.8 \mathrm{MPa}$. c) $G=1.2 \mathrm{MPa}$

\section{2 - Combined vertical and horizontal load}

The vertical stiffness of bearings under combined vertical and horizontal load is reduced due to the rollover: the marginal areas of the bearing detach from the supports, the contact area is reduced and consequently the vertical stiffness. The reduction of vertical stiffness involves an increase in the axial compressibility of the bearing. Figure 5 and Figure 6 show the trends of vertical stiffness with vertical and horizontal displacement, for $t_{e}=2 \mathrm{~mm}$ and $t_{e}=5 \mathrm{~mm}$. The left columns of the figures show the $K_{v}-\delta_{v}$ trends, while those on the right show the $K_{v}-\delta_{H}$ trends; each row refers to a different value of the shear modulus $G$.

As from Figure 3 and from Figure 4 it can be deduced that the trend of the vertical stiffness does not depend on the applied pressure (its effect is to increase the compression and, therefore, the vertical displacements), e.g. ${ }^{\sigma_{v}=8} \mathrm{MPa}$ was considered in Figure 5 and Figure 6. 
Compared to the vertical displacement, the stiffness is constant in a first part, where the horizontal displacement is zero. The horizontal extension of the constant stiffness section is smaller as $S_{2}$ increases, because the vertical stiffness increases.

Vertical stiffness is always decreasing as the horizontal displacement increases with an almost linear trend; this decrease is smaller for the higher values of $S_{2}$. Table 2 shows the average on the pressures and on the $G$ modulus of the ratios between the vertical stiffness at the generic level of horizontal displacement $\left(K_{v}\right)$ and that under pure compression $\left(K_{v}^{(0)}\right)$. Again, there is a difference in vertical response between bearings with $S_{2}$ lower and higher than 2.5:

- If $S_{2}>2.5$ : the vertical stiffness, even at large displacements, still anyway around the $50 \%$ of that under pure compression. This reduction tends to zero as $S_{2}$ increases, with a vertical stiffness at $\gamma_{H}=2.00$ for $S_{2}=5.00$ on average $17 \%$ lower than the stiffness under pure vertical load.

- If $S_{2} \leq 2.5$ : as $S_{2}$ decreases, the bearings is unstable before one of the selected thresholds of horizontal displacement and the computation of the vertical stiffness is meaningless. For bearings that reach full rollover, the vertical stiffness almost drops to zero.

As mentioned, the vertical stiffness must be sufficiently higher than the horizontal stiffness. Their ratio must have at least two orders of magnitude of difference. Considering a ratio between vertical stiffness under pure compression and horizontal stiffness equal to 500, this ratio is reduced under combined vertical and horizontal action according to Table 2. The numerical values are shown in Table 3. As can be seen, only where $S_{2}$ is at least equal to 2.5 this ratio remains greater than 100 up to full rollover. 

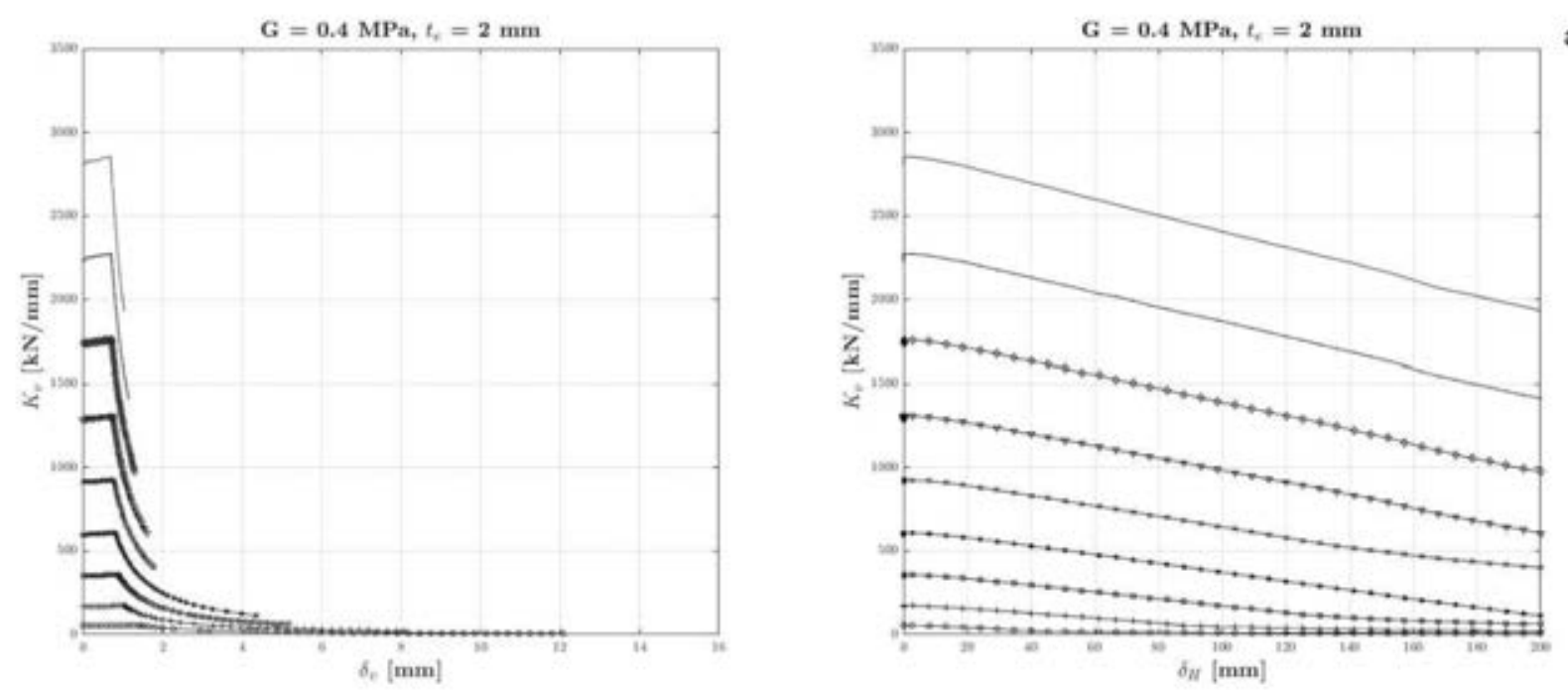

a)
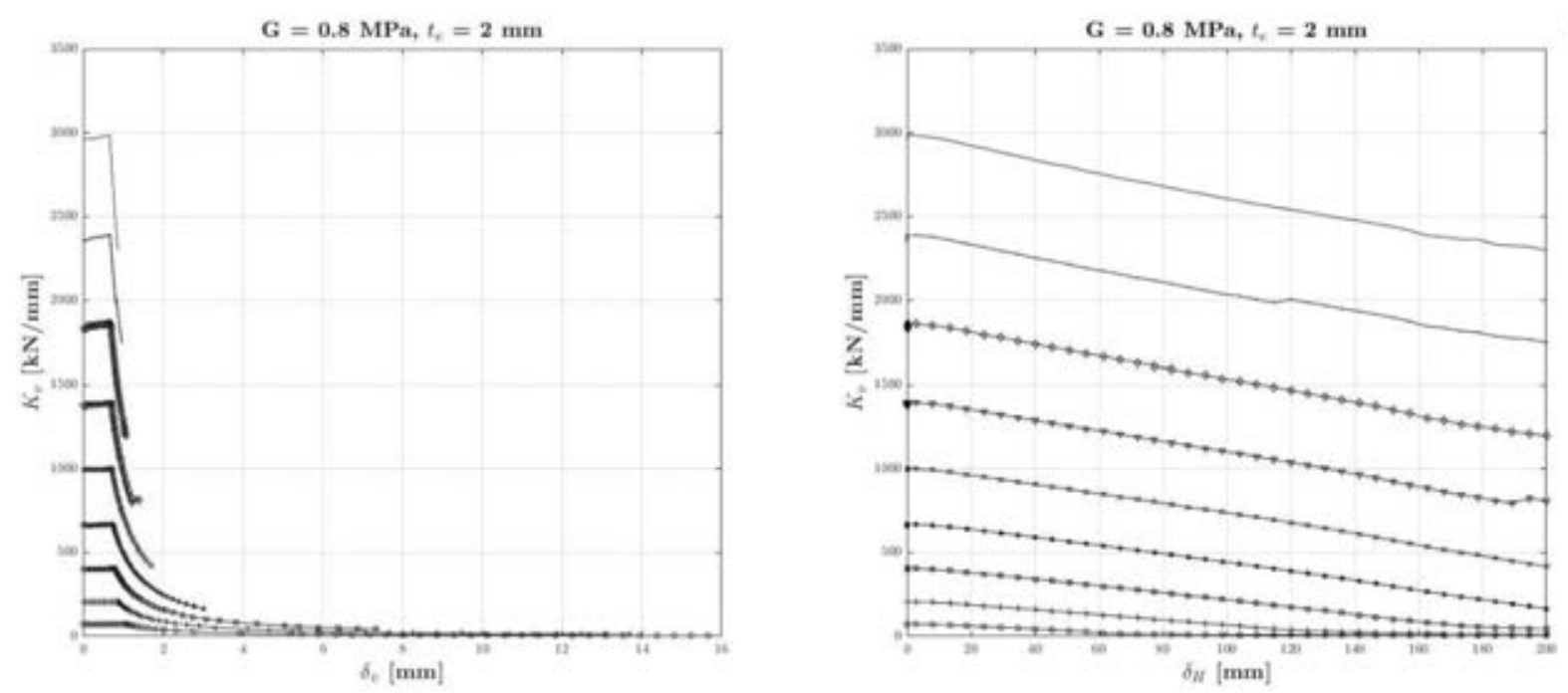

b)
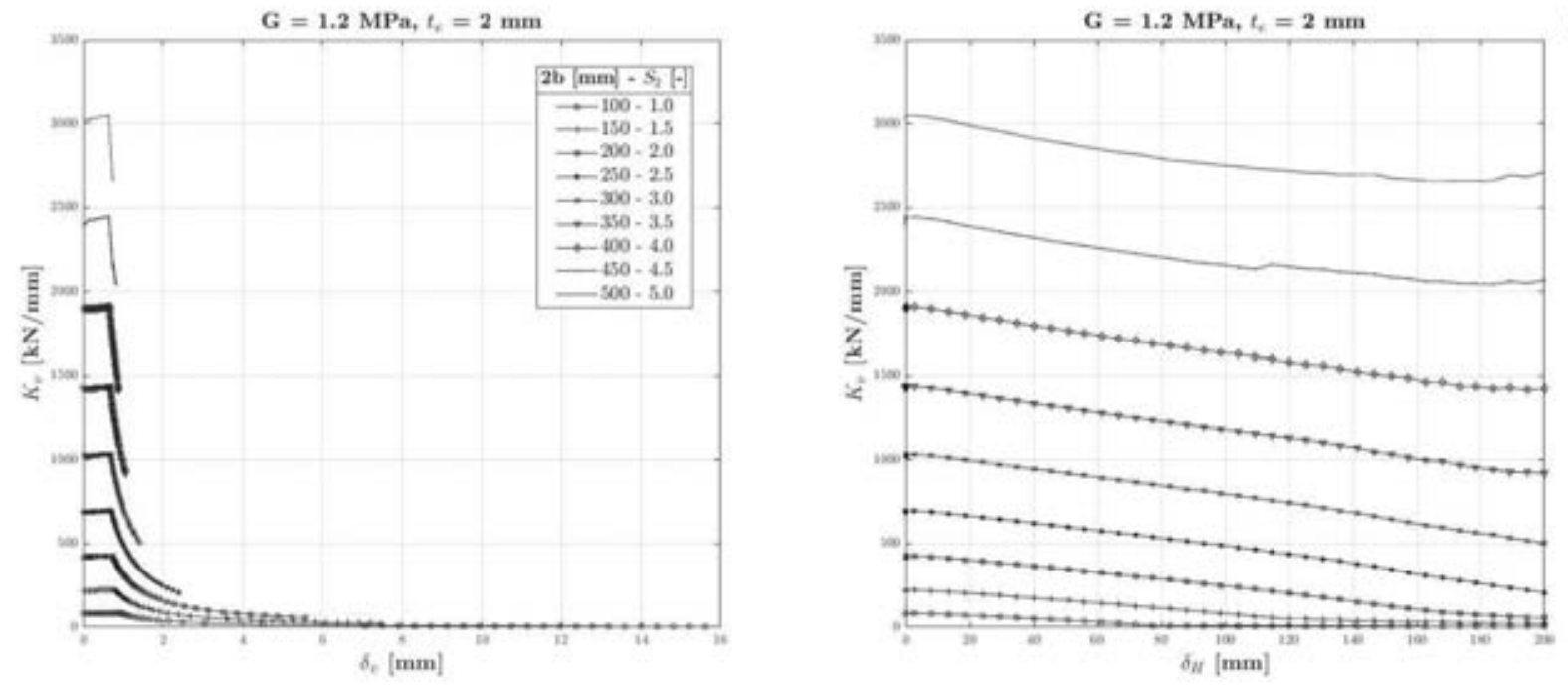

c)

Figure 5: Vertical stiffness variable with vertical and horizontal displacement, $t_{e}=2 \mathrm{~mm}:$ a) $G=0.4 M P a, b$ )

$$
G=0.8 \mathrm{MPa} \text {. c) } G=1.2 \mathrm{MPa} .
$$



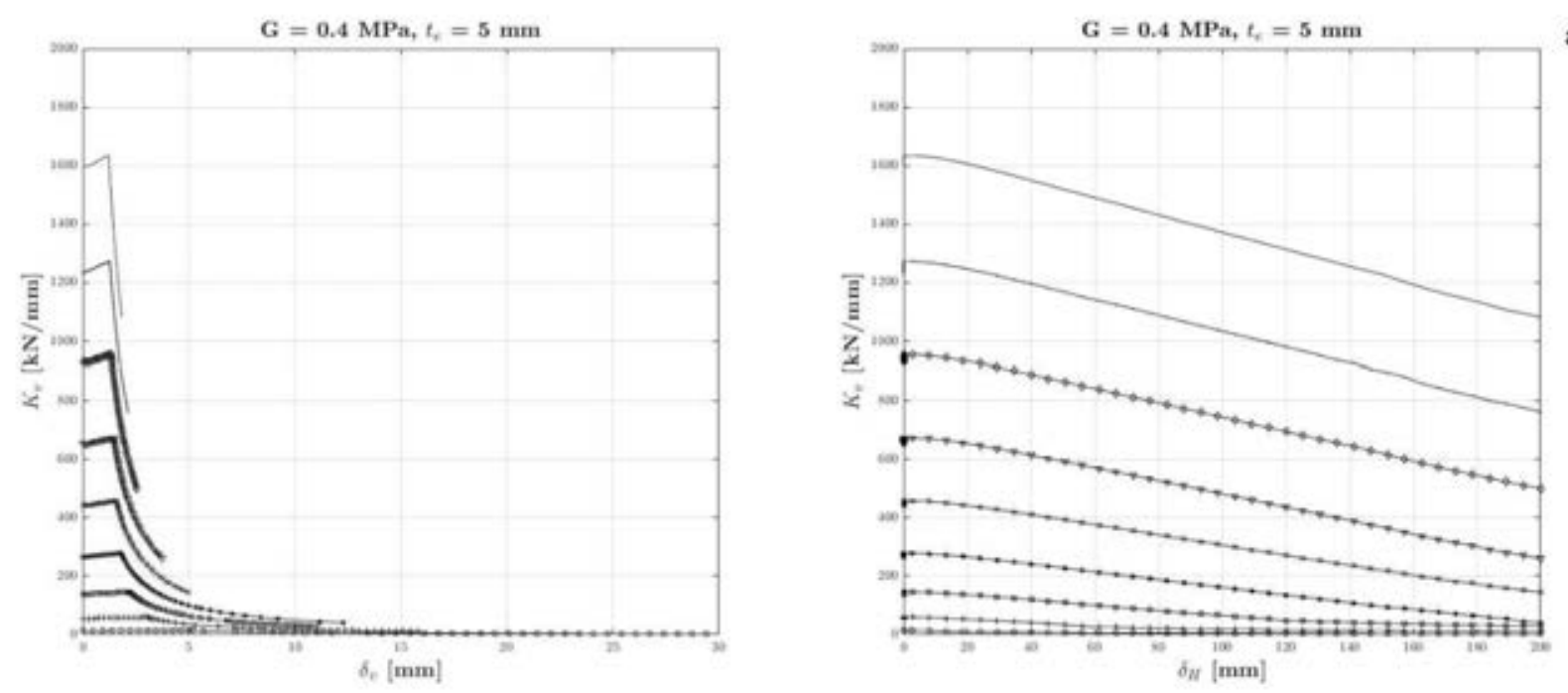

a)
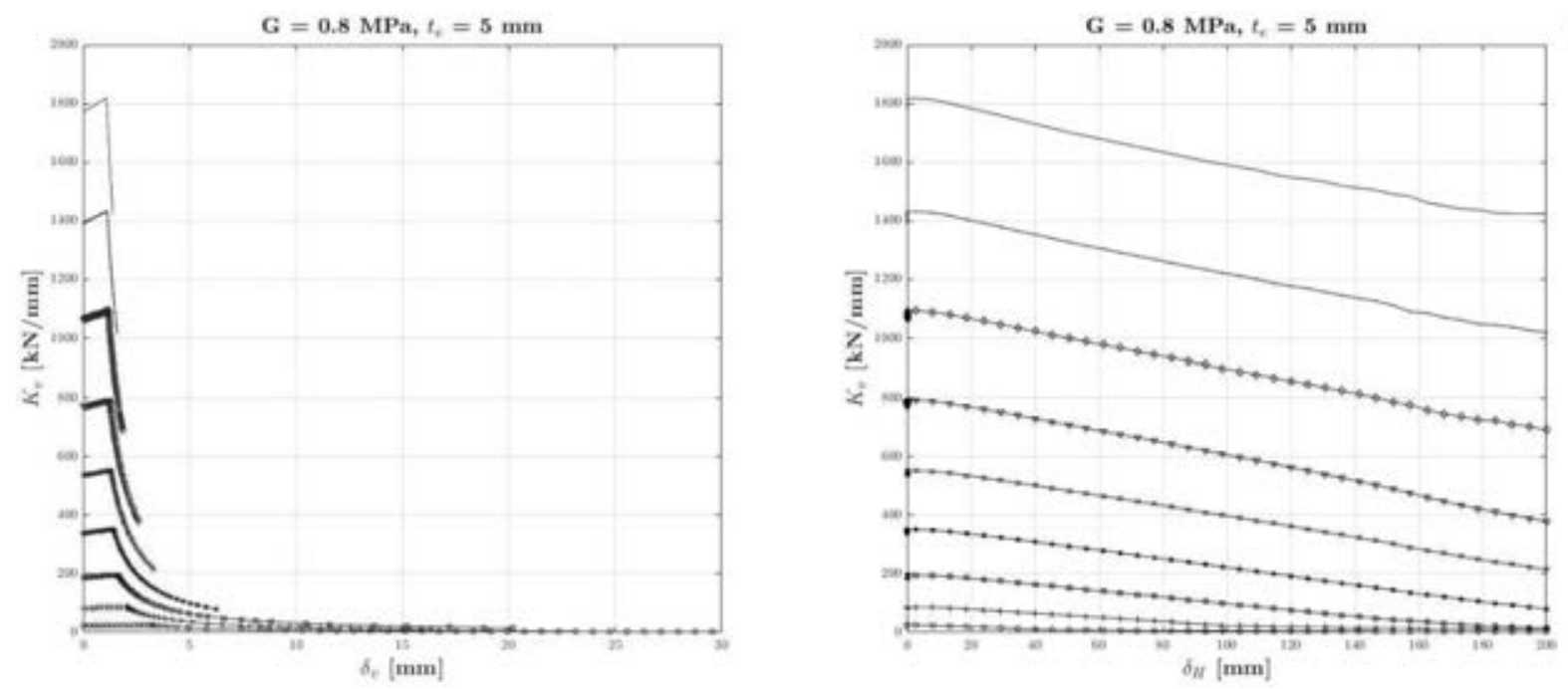

b)
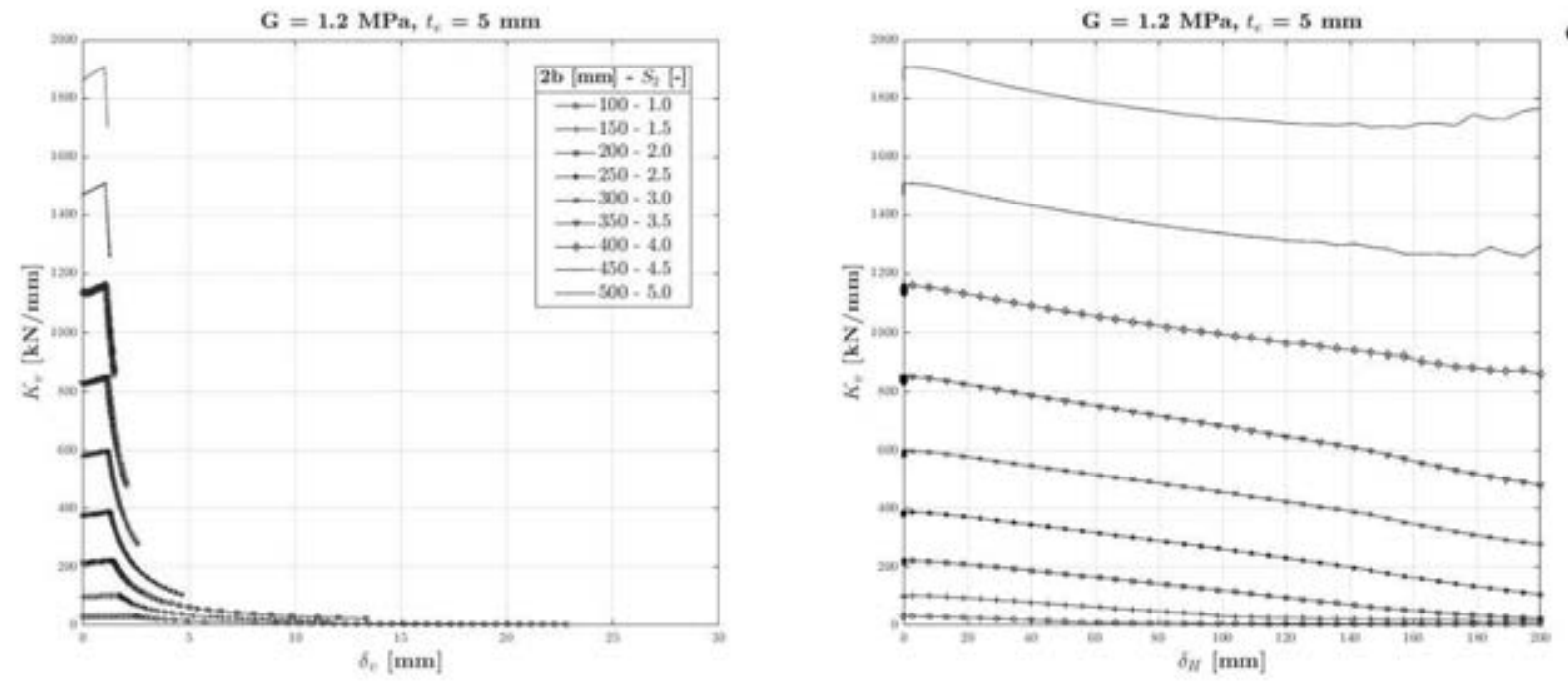

Figure 6: Vertical stiffness variable with vertical and horizontal displacement, $t_{e}=5 \mathrm{~mm}:$ a) $G=0.4 M P a, b$ )

$$
G=0.8 \mathrm{MPa} \text {. c) } G=1.2 \mathrm{MPa} .
$$


Table 2: Average $K_{v} / K_{v}^{(0)}$ ratios for different horizontal displacement levels.

\begin{tabular}{|c|c|c|c|c|c|c|c|c|c|}
\hline \multirow{3}{*}{$\gamma_{H}$} & \multicolumn{9}{|c|}{$S_{2}$} \\
\hline & 1.00 & 1.50 & 2.00 & 2.50 & 3.00 & 3.50 & 4.00 & 4.50 & 5.00 \\
\hline & \multicolumn{9}{|c|}{$K_{v} / K_{v}^{(0)}$} \\
\hline 0.00 & 1.00 & 1.00 & 1.00 & 1.00 & 1.00 & 1.00 & 1.00 & 1.00 & 1.00 \\
\hline 0.50 & 0.51 & 0.72 & 0.82 & 0.87 & 0.90 & 0.91 & 0.93 & 0.94 & 0.95 \\
\hline 1.00 & - & 0.28 & 0.54 & 0.67 & 0.75 & 0.80 & 0.84 & 0.86 & 0.89 \\
\hline 1.50 & - & - & 0.27 & 0.47 & 0.60 & 0.68 & 0.76 & 0.81 & 0.85 \\
\hline 2.00 & - & - & 0.03 & 0.25 & 0.43 & 0.56 & 0.69 & 0.76 & 0.83 \\
\hline \multicolumn{10}{|c|}{ Table 3: Examples of $K_{v} / K_{H}$ ratios for different horizontal displacement levels. } \\
\hline \multirow[b]{3}{*}{$\gamma_{H}$} & & & & & $S_{2}$ & & & & \\
\hline & 1.00 & 1.50 & 2.00 & 2.50 & 3.00 & 3.50 & 4.00 & 4.50 & 5.00 \\
\hline & \multicolumn{9}{|c|}{$K_{v} / K_{H}$} \\
\hline 0.00 & 500 & 500 & 500 & 500 & 500 & 500 & 500 & 500 & 500 \\
\hline 0.50 & 238 & 356 & 406 & 430 & 445 & 454 & 463 & 468 & 472 \\
\hline 1.00 & - & 111 & 262 & 325 & 365 & 389 & 412 & 427 & 437 \\
\hline 1.50 & - & - & 118 & 224 & 290 & 327 & 368 & 396 & 413 \\
\hline 2.00 & - & - & 33 & 116 & 209 & 260 & 320 & 364 & 392 \\
\hline
\end{tabular}

\section{FINITE ELEMENT ANALYSIS RESULTS: COMPRESSIVE MODULUS}

\section{1 - Pure compression}

The compressive modulus $E_{c}$ under pure compression depends solely on the mechanical and geometric properties of the bearing. Starting from the vertical stiffness obtained in $\S 3.1$, it is therefore possible to obtain the $E_{c}$ modulus under pure compression by varying both the geometry ( $\left.S_{1}, S_{2}\right)$ and the mechanical parameters $\left(G, \sigma_{v}\right)$, as follows:

$$
E_{c}\left(\delta_{H}=0\right)=\frac{K_{v} \cdot t_{r}}{A_{c}}
$$

where $t_{r}$ is the total rubber height and $A_{c}$ the contact area between bearing and support. Figure 7 and Figure 8, as done for vertical stiffness, show the trends of the compressive modulus under pure compression as the vertical pressure, secondary shape factor (primary axes, black curves) and primary shape factor vary (secondary axes, gray curves). Again, the vertical pressure does not affect the shape of the curves, making these translate horizontally (black curves) or vertically (gray curves). The secondary shape factor affects the response under pure compression only for low values $\left(S_{2}<2.5\right.$, while for high values the compressive modulus seems to converge to a common value for a fixed $G$ and $\sigma_{v}$. Finally, the $G$ modulus clearly affects the compressibility of the bearing, more significantly when the thickness of the elastomeric layer is greater. 


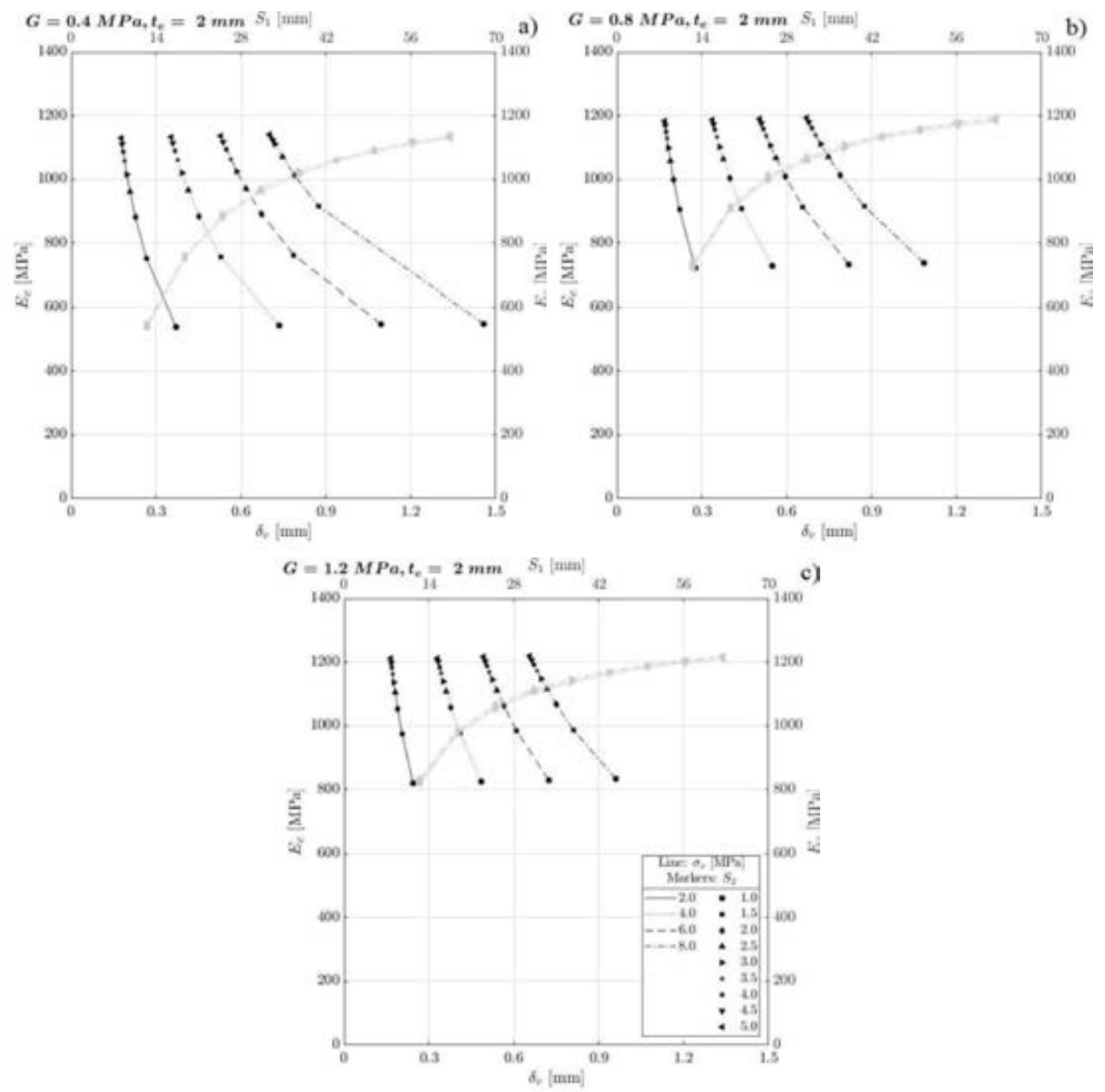

Figure 7: Effective compressive modulus under pure compression for different vertical pressure, primary and secondary shape factor, $t_{e}=2 \mathrm{~mm}$ : a) $G=0.4 \mathrm{MPa}$, b) $G=0.8 \mathrm{MPa}$. c) $G=1.2 \mathrm{MPa}$ 

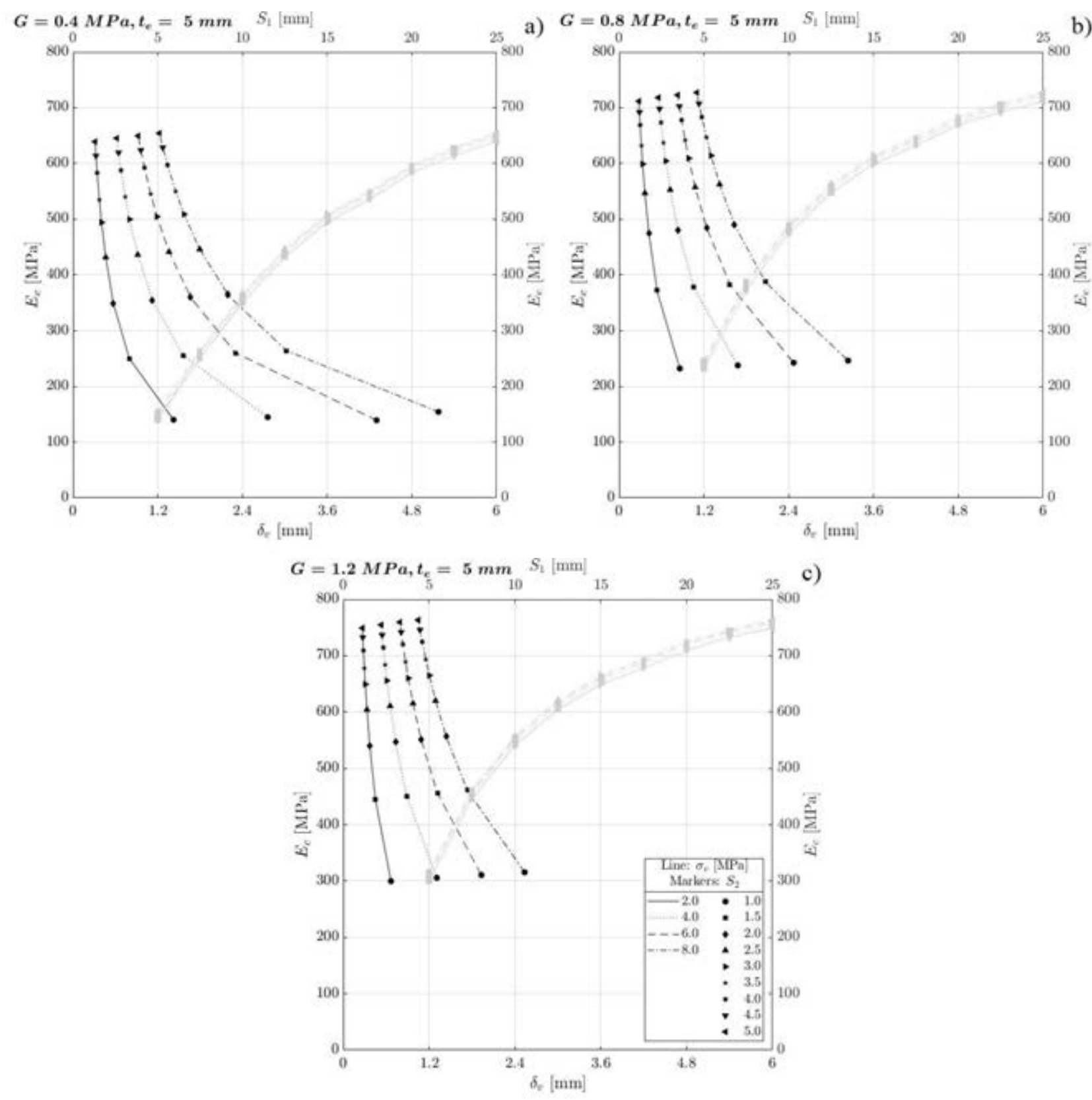

Figure 8: Effective compressive modulus under pure compression for different vertical pressure, primary and secondary shape factor, $t_{e}=5 \mathrm{~mm}$ : a) $G=0.4 \mathrm{MPa}$, b) $G=0.8 \mathrm{MPa}$. c) $G=1.2 \mathrm{MPa}$

\section{2 - Combined vertical and horizontal load}

The effective compressive modulus $E_{c}$ of the bearings under combined axial and shear load was determined as follow:

$$
E_{c}\left(\delta_{H}\right)=\frac{K_{v} \cdot t_{r}}{A_{c}\left(\delta_{H}\right)}=\frac{F_{v} \cdot t_{r}}{\delta_{v}\left(\delta_{H}\right) \cdot A_{c}\left(\delta_{H}\right)}
$$

being $F_{v}=\sigma_{v} \cdot A$ the vertical applied force and $\delta_{v}$ the total vertical displacement at the top of the bearing. During horizontal displacement, the total vertical displacement and the contact area vary, increasing and decreasing respectively, resulting functions of the horizontal displacement. Since the 
vertical displacement increases as the horizontal displacement increases while the contact area decreases, the $E_{c}$ modulus can either decrease or increase.

Figure 9 and Figure 10 show the trends of the $E_{c}$ modulus with the horizontal displacement. Again, a dual range can be defined by the secondary shape factor:

- If $S_{2} \leq 2.5$ : the modulus has a strictly decreasing trend with the horizontal displacement, the more marked the lower is $S_{2}$. This is because the vertical displacement in formula (4.2) increases faster than the contact area decreases.

- If $S_{2}>2.5$ : the $E_{c}$ modulus is constant in a first section up to a horizontal displacement around $150 \mathrm{~mm}$, then $E_{c}$ rapidly decreases. In the first section, the variations in vertical displacement and contact area are almost equivalent, so the modulus varies little noticeably. In the second section, due to the full rollover, the contact area increases and the $E_{c}$ modulus can only decrease. 


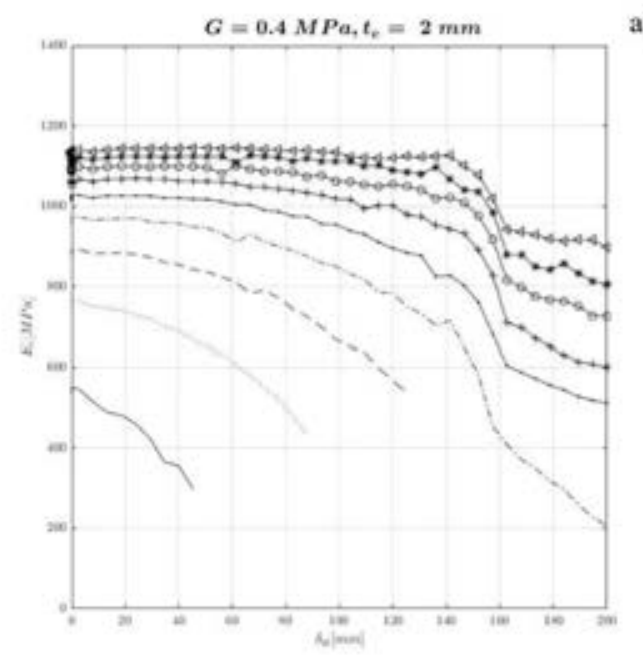

a)

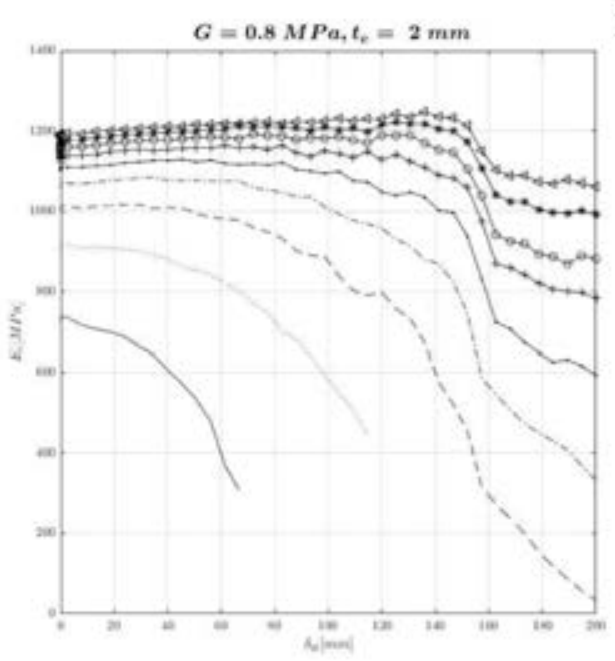

b)

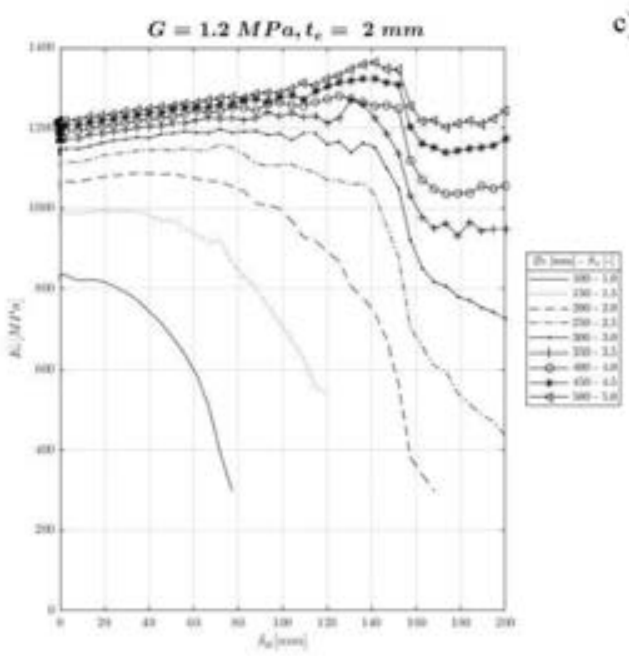

Figure 9: Effective compressive modulus vs horizontal displacement, $t_{e}=2 \mathrm{~mm}$ : a) $G=0.4 \mathrm{MPa}$, b) $G=0.8 \mathrm{MPa}$ .c) $G=1.2 \mathrm{MPa}$. 


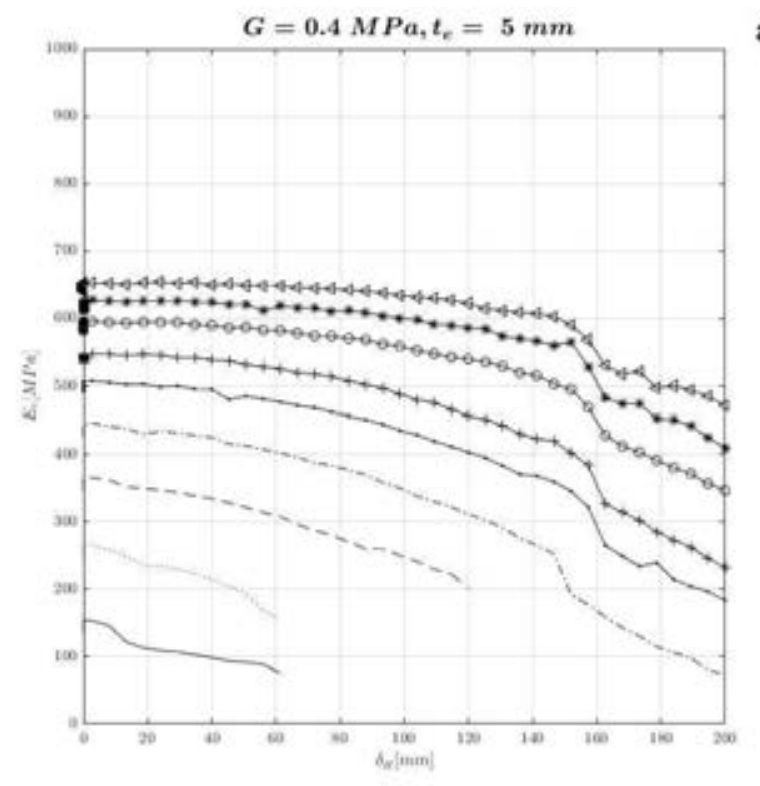

a)

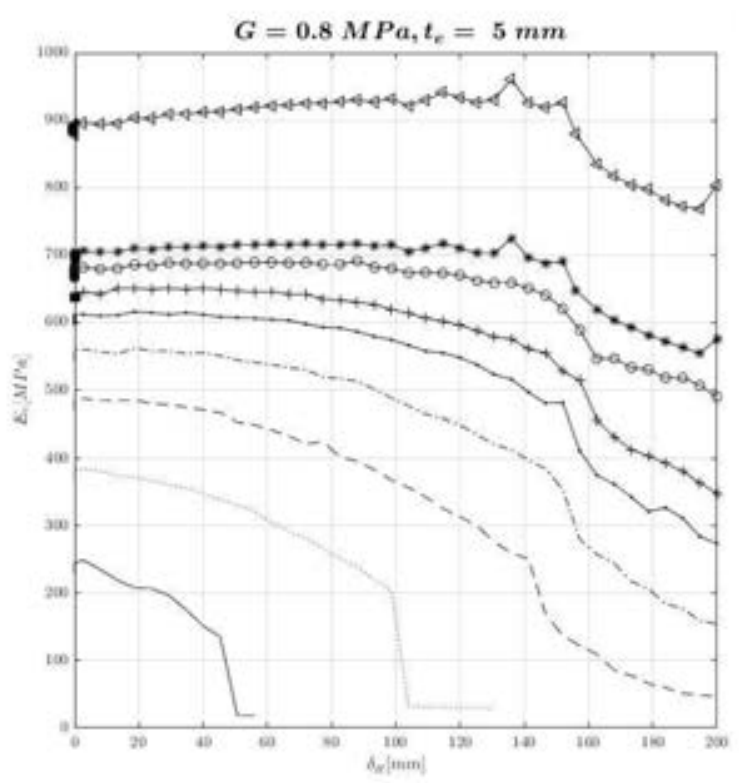

b)

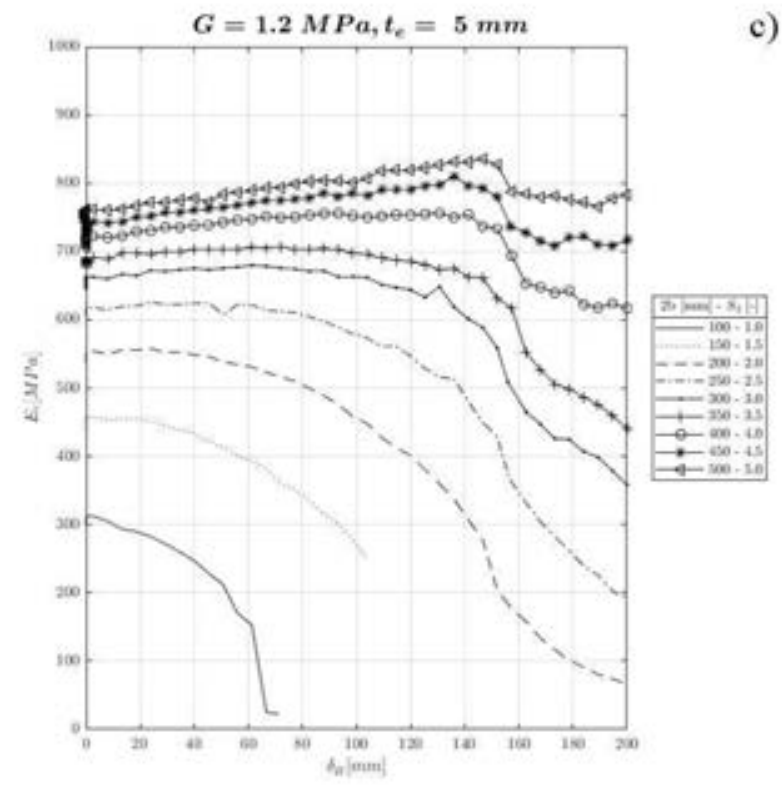

c)

Figure 10: Effective compressive modulus vs horizontal displacement, $t_{e}=5 \mathrm{~mm}:$ a) $\left.G=0.4 M P a, b\right)$

$$
G=0.8 \mathrm{MPa} \text {.c) } G=1.2 \mathrm{MPa} \text {. }
$$

\section{CONCLUSIONS}

The vertical response of a large number of fiber-reinforced elastomeric isolators was analyzed in this paper, i.e. vertical stiffness and effective compressive modulus have been studied into details. Two conditions of variation of the vertical properties were considered: vertical properties both under pure compression and combined vertical and horizontal load. The geometric and mechanical factors considered allowed to draw general conclusions on the variability of the vertical response. The bearings exhibit a response mainly dependent on geometry rather than on applied pressure; the mechanical parameters influence the magnitude of the response but not the shape, which is preserved. The main role of the primary shape factor $S_{1}$ on the vertical response of a single bearings under pure compression is confirmed. When the bearing is subjected to simultaneous 
vertical and horizontal action, the secondary shape factor $S_{2}$ plays a key role, particularly affecting the stability of the bearing. A transition value approximately equal to 2.5 can be found, which separates the response of stable from unstable bearings. Unstable bearings show a rapid decrease in vertical stiffness and effective compressive modulus; in stable bearings the vertical response parameters decrease less noticeably as the lateral stiffness increases. It is essential that the vertical stiffness tends to be higher than horizontal stiffness even under lateral deformation: this requirement tend to be met by bearings with a secondary shape factor greater than 2.5 .

\section{REFERENCES}

[1] J. M. Kelly, "Analysis of Fiber-Reinforced Elastomeric Isolators," Journal of Seismology and Earthquake Engineering, vol. 2, no. 1, 1999.

[2] B. Y. Moon, G. J. Kang, B. S. Kang and J. M. Kelly, "Design and manufacturing of fiber reinforced elastomeric isolator for seismic isolation," Journal of Materials Processing Technology, vol. 130, no. 131, pp. 145-150, 2002.

[3] B. Y. Moon, G. J. Kang, B. S. Kang, G. S. Kim and J. M. Kelly, "Mechanical properties of seismic isolation system with fiber-reinforced bearing of strip type," International Applied Mechanics, vol. 39, no. 10, pp. 1231-1239, 2003.

[4] J. M. Kelly and M. S. Takhirov, "Analytical and experimental study of fiber-reinforced elastomeric isolators," PEER Report 11, Pacific Earthquake Engineering Research Center, College of Engineering, University of California Berkeley, 2001.

[5] H. Toopchi-Nezhad, M. J. Tait and R. G. Drysdale, "Testing and modeling of square carbon fiber-reinforced elastomeric seismic isolators," Structural Control and Health Monitoring, vol. 15, pp. 876-900, 2007.

[6] H. Toopchi-Nezhad, M. J. Tait and R. G. Drysdale, "Bonded versus unbonded strip fiber reinforced elastomeric isolators: Finite element analysis," Composite Structures, vol. 93, pp. 850-859, 2011.

[7] H. C. Tsai and J. M. Kelly, "Stiffness analysis of fiber-reinforced elastomeric isolators," PEER Report 05, Pacific Earthquake Engineering Research Center, College of Engineering, University of California Berkeley, 2001.

[8] H. C. Tsai, "Compression stiffness of infinite-strip bearings of laminated elastic material interleaving with flexible reinforcements," International Journal of Solids and Structures, vol. 41, pp. 6647-6660, 2004.

[9] H. C. Tsai, "Compression stiffness of circular bearings of laminated elastic material interleaving with flexible reinforcements," International Journal of Solids and Structures, vol. 43, pp. 3484-3497, 2006.

[10] H. C. Tsai and J. M. Kelly, "Buckling of short beams with warping effect included," International Journal of Solids and Structures, no. 42, pp. 239-253, 2005. 
[11] H. C. Tsai and J. M. Kelly, "Buckling load of seismic isolators affected by flexibility of reinforcement," International Journal of Solids and Structures, no. 42, pp. 255-269, 2005.

[12] G. Russo, M. Pauletta and A. Cortesia, "A study on experimental shear behavior of fiberreinforced elastomeric isolators with various fiber layouts, elastomers and aging conditions," Engineering Structures, vol. 52, pp. 422-433, 2013.

[13] N. C. Van Engelen, M. J. Tait and D. Konstantinidis, "Model of the Shear Behavior of Unbonded Fiber-Reinforced Elastomeric Isolators," Journal of Structural Engineering, vol. 141, no. 7, 2015.

[14] A. Calabrese, G. Serino, S. Strano and M. Terzo, "Experimental investigation of a low-cost elastomeric anti-seismic device using recycled rubber," Meccanica, no. 50, pp. 2201-2218, 2015.

[15] D. Losanno, M. Spizzuoco and A. Calabrese, "Bidirectional shaking-table tests of unbonded recycled-rubber fiber-reinforced bearings (RR-FRBs)," Structural Control and Health Monitoring, vol. 26, no. 9, p. e2386, 2019.

[16] D. Losanno, I. E. Sierra Madera, M. Spizzuoco, J. Marulanda and P. Thomson, "Experimental assessment and analytical modeling of novel fiber-reinforced isolators in unbounded configuration," Composite Structures, no. 212, pp. 66-82, 2019.

[17] D. Losanno, A. Calabrese, I. E. Madera Sierra, M. Spizzuoco, J. Marulanda, P. Thomson and G. Serino, "Recycled Versus Natural-Rubber Fiber-Reinforced Bearings for Base Isolation: Review of the Experimental Findings," Journal of Earthquake Engineering, 2020.

[18] D. Losanno, I. E. Madera Sierra, M. Spizzuoco, J. Marulanda and P. Thomson, "Experimental performance of unbonded polyester and carbon fiber reinforced elastomeric isolators under bidirectional seismic excitation," Engineering Structures, no. 209, p. 110003, 2020.

[19] I. E. Madera Sierra, D. Losanno, S. Strano, J. Marulanda and P. Thomson, "Development and experimental behavior of HDR seismic isolators for low-rise residential buildings," Engineering Structures, no. 183, pp. 894-906, 2019.

[20] D. Losanno, F. Palumbo, A. Calabrese, T. Barrasso and N. Vaiana, "Preliminary investigation of aging effects on Recycled Rubber Fiber Reinforced Bearings (RR-FRBs)," Journal of Earthquake Engineering, no. DOI: 10.1080/13632469.2021.1871683, 2021.

[21] A. Calabrese, D. Losanno, M. Spizzuoco, S. Strano and M. Terzo, "Recycled Rubber Fiber Reinforced Bearings (RR-FRBs) as base isolators for residential buildings in developing countries: The demonstration building of Pasir Badak, Indonesia," Engineering Structures, no. 192, pp. 126-144, 2019.

[22] J. M. Kelly and A. Calabrese, "Analysis of Fiber-Reinforced Elastomeric Isolators Including Stretching of Reinforcement and Compressibility of Elastomer.," Ingegneria Sismica, vol. 30, no. 3, pp. 5-14, 2013.

[23] Y. Al-Anany and M. J. Tait, "A numerical study on the compressive and rotational behavior of fiber reinforced elastomeric isolators (FREI)," Composite Structures, no. 133, pp. 1249-1266, 
2015.

[24] A. Calabrese, M. Spizzuoco, S. Galano, N. Tran, S. Strano and M. Terzo, "A Parametric Study on the Stability of Fiber Reinforced Rubber Bearings Under Combined Axial and Shear Loads," Engineering Structures, vol. 227, p. 111441, 2020.

[25] D. Losanno, N. Ravichandran, F. Parisi, A. Calabrese and G. Serino, "Seismic performance of a Low-Cost base isolation system for unreinforced brick Masonry buildings in developing countries," Soil Dynamics and Earthquake Engineering, no. 141, p. 106501, 2021.

[26] N. Vaiana, S. Sessa, M. Paradiso and L. Rosati, "Accurate and efficient modeling of the husteretic behavior of sliding bearings," in Proceedings of the 7th ECCOMAS thematic conferenc on Computational Methods in Structural Dunamics and Earthquake Engineering, Compdyn 2019, 2019.

[27] S. Sessa, N. Vaiana, M. Paradiso and L. Rosati, "An inverse identification strategy for the mechanical parameters of a phenomenological hysteretic constitutive model," Mechanical Systems and Signal Processing, vol. 139, p. 106622, 2020.

[28] F. Marmo, S. Sessa, N. Vaiana, D. De Gregorio and L. Rosati, "Complete solutions of three dimensional problems in transversely isotropic media," Continuum Mechanics and Thermodynamics, vol. 32, no. 3, pp. 775-802, 2020.

[29] N. Vaiana, S. Sessa and L. Rosati, "A generalized class of uniaxial rate-independent models for simulating asymmetric mechanical hysteresis phenomena," Mechanical Systems and Signal Processing, vol. 146, p. 106984, 2021.

[30] N. Vaiana, D. Losanno and N. Ravichandran, "A novel family of multiple springs models suitable for biaxial rate-independent hysteretic behavior," Computers \& Structures, vol. 244, p. $106403,2021$.

[31] J. M. Kelly and D. Konstantinidis, Mechanics of Rubber Bearings for Seismic Isolation and Vibration Isolation, John Wiley and Sons, Ltd, 2011.

[32] H. Toopchi-Nezhad, M. J. Tait and R. G. Drysdale, "Lateral Response Evaluation of FiberReinforced Neoprene Seismic Isolators Utilized in an Unbonded Application," JOURNAL OF STRUCTURAL ENGINEERING, vol. 10, no. 134, pp. 1627-2637, 2008.

[33] ASCE-7. Minimum design loads for buildings and other structures, ASCE/SEI 7-, 2010.

[34] UNI EN 1998-1:2013 Part 1, 2013.

[35] Aggiornamento delle «Norme tecniche per le costruzioni», 2018.

[36] H. Toopchi-Nezhad, R. G. Drysdale and M. J. Tait, "Parametric Study on the Response of Stable Unbonded-Fiber Reinforced Elastomeric Isolators (SU-FREIs)," Journal of Composite Materials, vol. 43, no. 15, 2009.

[37] M. G. De Raaf, M. J. Tait and H. Toopchi-Nezhad, "Stability of fiber-reinforced elastomeric bearings in an unbonded application," Journal of Composite Materials, vol. 45, no. 18, pp. 
1873-1884, 2011.

[38] S. Galano, D. Losanno and A. Calabrese, Stability Analysis of Unbonded Fiber Reinfoced Isolators of Square Shape, Under review. Submitted to Engineering Structures, 2021.

[39] F. Naeim and J. M. Kelly, Design of seismic isolated structures, John Wiley \& Sons, Inc., 1999.

[40] P. M. Osgooei, D. Konstantinidis and M. J. Tait, "Variation of the vertical stiffness of stripshaped fiber-reinforced elastomeric isolators under lateral loading," Composite Structures, vol. 144, pp. 177-184, 2016.

[41] MSC.Software Corporation, MSC.Marc Mentat release guide, Santa Ana, CA, USA, 2005.

[42] MSC.Software Corporation, MAR103 Experimental Elastomer Analysis, Santa Ana, CA, USA, 2017.

[43] MSC.Software Corporation, Volume B: Element Library, Santa Ana, CA, USA, 2017.

[44] J. M. Kelly and D. Konstantinidis, "Effect of Friction on Unbonded Elastomeric Bearings," Journal of Engineering Mechanics, vol. 135, no. 9, pp. 953-960, 2009. 